\title{
ICT as a tool for learning to learn
}

\author{
Paola Forcheri and Maria Teresa Molfino \\ Istituto per la Matematica Applicata, Consiglio Nazionale delle Ricerche, Via de Marini 6, \\ 16149 Genova, Italy.forcheri@ima.ge.cnr.it
}

Keywords: autonomous learning, information communication technology, lifelong learning, education systems

\begin{abstract}
The paper discusses the potential of ICT (Information Communication Technology) as a tool for autonomous learning, and suggests approaches to follow that will allow the education system to exploit this potential. In particular, we will analyse the key factors at the basis of autonomous learning, and will discuss the difficulties which prevent the education system from helping people learn to learn. We will then analyse the effects of ICT on learning from two points of view, the changes in the education system and the motivational effects. The educational potential of ICT will then be discussed according to the key elements of autonomous learning's education factors, and examples of applications will be shown, relating ICT based activities to these elements. The analysis of the role which should be played by educator to render these activities effective from an autonomous learning point of view will complete the discussion.
\end{abstract}

\section{INTRODUCTION}

Present trends in the job market require people to adapt their knowledge and skills to changes in the workplace, thus making it crucial to have access to lifelong autonomous learning (European Commission 1995a). Notwithstanding this situation, neither the scholastic nor the training system, at least in Italy, includes education for autonomous learning among its objectives. Several factors underlie this problem: the lack of a widespread culture of autonomous learning; the difference between the instructional model usually implemented by the education system and the self-learning model; the difficulty for motivating people for self-learning, especially in the case of topics requiring time and effort; and the difficulty of creating, 
within an educational structure, an effective context to support autonomous learning.

The increasing importance of lifelong learning, however, gives impulse to projects regarding the design and testing of new learning models for the development of skills and essential knowledge to support autonomous learning (European Commission 1995b). The experience gained through these and other projects gives numerous indications about the potential of Information Communication Technology (ICT) as a tool for autonomous learning, and suggests approaches to follow that will allow the education system to exploit this potential.

In this paper we will discuss some of these aspects, beginning with a brief analysis of the keys factors at the basis of autonomous learning. We will then go on to discuss the difficulties which prevent the education system, embracing both schooling and training, from helping people learn to learn. We will then analyse the effects of ICT on learning from two points of view, the changes in the education system and the motivational effect. The educational potential of ICT will then be discussed according to the key elements of autonomous learning's education factors, and examples of applications will be shown.

\section{AUTONOMOUS LEARNING}

Autonomous learning requires a positive attitude towards learning and a number of capabilities.

Among the key factors of a positive attitude we include motivation, selfconfidence and sense of responsibility. Among the capabilities, we include evaluation of personal difficulties and learning strategies, awareness of the gap between the knowledge already acquired and that to be acquired, construction of new knowledge starting from the existing one, identification of reasonable objectives and of the time needed to reach them, use of a methodological approach to learning, recognition and use of learning sources tailored to needs.

Time, organisational and institutional problems inherent in the educational setting often make it difficult to acquire the necessary positive attitude and capability. However, an education system can be designed to help people acquire these capabilities, at least to some extent. ICT constitutes a valuable support in this direction, as it introduces changes in the educational setting and increases motivation.

\subsection{Changes in the educational setting}

ICT suggests both new approaches to learning and new forms of interaction, thus modifying relationships in the classroom (Balacheff 1993). 
As to learning, a typical example is the possibility of getting learners to handle real problems using simulation systems to analyse situations that are difficult, costly or too dangerous to handle in practice Hampel et al. 1998). As to interaction, we note that lab activity, which constitutes a central aspect of the use of technology, creates favourable conditions that help educators and learners create a climate of collaborative knowledge construction, thus modifying their traditional roles (Bottino et al. 1999).

To make the change in the educational setting effective, however, educators have to be trained on how effectively to use new technologies in their work (Bottino et al. 1998). Training must overcome the view of technology simply as a commodity useful for solving given practical problems. It must also be pointed out that computational environments can be useful tools in the educational process, but learning to use them takes time, and may involve specific pedagogical and epistemological decisions (Noss 1995). In the school context, moreover, teachers should be helped to establish links with the industrial world to understand operatively real technology applications (Kommers et al. 1996; Blandow and Dyrenfurth 1994).

Finally, educators themselves should experiment with the new possibilities offered by ICT. For example, technology can be used as a means to help teachers to carry out autonomous in-service training, individually or collaboratively. In this respect, we recall a recent project of the Italian Ministry of Education, for the design and production of a multimedia system for the self-training of mathematics teachers. The system analyses the conceptual difficulties involved in several mathematical topics, proposes keys for interpreting them and suggests questions that should be examined in designing activities to overcome them. The problem of comparing the different interpretations, answering the questions, and relating the activities to classroom teaching is left to the teacher. The system was tested with about 40 teachers of the different Italian regions: the results were encouraging in that teachers demonstrated interest in tools aimed at stimulating autonomous reflection on teaching rather than in receiving teaching models (Arezzo et al. 1998).

\subsection{Motivations}

In the first years of life, babies have considerable capacity for autonomous learning, as they are highly motivated by the immediate advantage thus gained. The same does not apply to schools, nor to training on the job.

School students usually do not see a concrete link between schooling and the outside world. Moreover, it is difficult to help them find motivations for 
learning, as these strongly depend on individual feelings, and 'objective' factors (such as the idea that learning is an investment for the future) are not always sufficient. However, we note that, generally, ICT stimulates students' curiosity and creativity, poses problems they usually find challenging, and represents a link between the school and the outside world, thus constituting a motivating tool (Rekkedal 1998).

Given these considerations, we seek to familiarise students with autonomous learning through activities centred on the learning of ICT. For example, companies can organise summer work experience courses devoted to helping students get to know the outside world and employ the knowledge acquired in school to the creation of an effective product. Such experiences are uncommon in Italy, but last year we carried out one at IMA in Genova: two seventeen year old students spent a month at the Institute working on the design and creation of part of the IMA web presentation (http://www.ima.ge.cnr.it/PROGETTI/ADAPT/adapt-bis.html). The kind of activity and the context helped these students develop sense of responsibility, the capability to evaluate the gap between their knowledge and that to be acquired, and the ability to evaluate the time needed to reach a given objective.

\section{TWO APPROACHES TO AUTONOMOUS LEARNING THROUGH ICT}

From an educational point of view, ICT can be used in accordance with both the individual and social views of learning, two perspectives which must be integrated to develop the abilities that form the basis for autonomous learning (see Table 1).

Table 1. Approaches to learning and autonomous learning capabilities

\begin{tabular}{ll}
\hline Individual learning & Social Learning \\
\hline Looking inwards & Looking outwards \\
Reflection on learning strategies & Learning from each other \\
Discovery of personal objective & Comparison of experiences \\
Awareness of personal potentiality & Discovery of external sources of learning \\
Use of personal resources & Awareness of knowledge \\
Self-evaluation & Use of the personal to reach a common objective \\
& Learning to be rated by others \\
& Integration of individual views \\
& Sense of responsibility \\
& Time and objective evaluation
\end{tabular}

The individual approach helps people reflect about themselves, thus helping to develop independence and personal initiative. On the other hand, 
the social approach fosters a strategic approach to problem solving and flexibility in handling a task. In several cases, the flexibility of ICT permits both the approaches: for example, multimedia systems can be employed in both individual and collaborative learning. In the following, for sake of simplicity, we suggest uses of each kind of technology considered according the approach to learning that it is best suited to (see Table 2).

Table 2. Technology and educational uses

\begin{tabular}{lll}
\hline & Learners' activities & Technology \\
\hline \multirow{3}{*}{ Individual learning } & Individualised self-learning & Multimedia tools \\
& Analysis of different material & Simulation environments \\
& Search & Web browsing \\
& Role-play activities & Teleconferencing systems \\
Social learning & Assignments & Email \\
& Articulated projects & Discussion lists \\
& Problem solving & Chat \\
& Management & Application environments \\
& & Computer lab equipment \\
\hline
\end{tabular}

Finally, we have to note that the teachers' use of ICT to co-ordinate the classroom work helps them to assume the role needed to encourage students to acquire autonomous learning capabilities (see Table 3). To this aim, in fact, teachers have to act as facilitators and providers of stimuli, rather than driving the educational process. In our opinion, psychological reasons and habits make it difficult to act in this way when working in a classroom. Communication technology makes it possible to maintain contact between teacher and students but, at the same time, the physical distance naturally gives students more independence from the teacher.

\subsection{Learning as an individual activity}

Individualised self-learning. Multimedia self-learning systems can be fruitfully used to encourage people to acquire initiative and to autonomously build active knowledge (Kommers et al. 1996) One example is Looking for Work, a self-learning tool aimed at orienting people in the activity of jobhunting: this activity requires autonomous learning capabilities such as personal initiative, setting objectives, deciding strategies, looking for useful information, etc. To encourage users to acquire these capabilities, the tool assists them in building a job-hunting strategy tailored to their personal needs and attitudes. Experimental uses of the tool have produced very interesting results: when asking for further help from those in the work orientation sector, users are submitting to them plans on how to move and are aware of their needs. In view of its success, the tool can now be 
consulted in numerous public institutions in our region and is to be adopted at national level (Forcheri et al. 1997).

Table 3. Activities, role of the educator and educator's use of ICT

\begin{tabular}{|c|c|c|}
\hline Learners' activities & Educator's role & Educator's use of ICT \\
\hline Individualised self- & Indicate the tool & Private email \\
\hline learning & Monitor the activity & $\begin{array}{l}\text { Analysis of student's } \\
\text { history } \\
\text { Chat }\end{array}$ \\
\hline Analysis of & Suggest a range of tools & Analysis of student's \\
\hline different material & Monitor the activity & $\begin{array}{l}\text { history } \\
\text { Use of a shared data-base } \\
\text { Private email }\end{array}$ \\
\hline Search & $\begin{array}{l}\text { Engage a discussion, based on the } \\
\text { learner' previous experience }\end{array}$ & $\begin{array}{l}\text { Discussion list } \\
\text { Email }\end{array}$ \\
\hline Role-play & $\begin{array}{l}\text { Assign the activity } \\
\text { Solicit any work involved }\end{array}$ & $\begin{array}{l}\text { Mailing lists } \\
\text { Discussion lists } \\
\text { Electronic repository }\end{array}$ \\
\hline Teaching & $\begin{array}{l}\text { Monitor the activity } \\
\text { Give help on demand }\end{array}$ & $\begin{array}{l}\text { Discussion lists } \\
\text { Frequently asked questions } \\
\text { Private email }\end{array}$ \\
\hline $\begin{array}{l}\text { Articulated } \\
\text { projects }\end{array}$ & $\begin{array}{l}\text { Suggest a theme, based on the learners' } \\
\text { interests }\end{array}$ & $\begin{array}{l}\text { Electronic repository } \\
\text { Shared data base }\end{array}$ \\
\hline & $\begin{array}{l}\text { Ask learners to organise the work and } \\
\text { take over the management of the whole } \\
\text { project } \\
\text { Take part in the project (without } \\
\text { management responsibility) } \\
\text { Ask learners to choose the programme } \\
\text { to use, from those available } \\
\text { Give help on-demand }\end{array}$ & Shared mailing list \\
\hline Problem solving & $\begin{array}{l}\text { Set the assignment } \\
\text { Guide the learners' work by means of } \\
\text { explanations, further material, etc.. }\end{array}$ & $\begin{array}{l}\text { Private and public mail } \\
\text { Electronic repository }\end{array}$ \\
\hline Management & $\begin{array}{l}\text { Set the task } \\
\text { Monitor the learners' work } \\
\text { Take the control of the lab } \\
\text { Give help on-demand }\end{array}$ & $\begin{array}{l}\text { Email } \\
\text { Chat } \\
\text { Video-conferencing }\end{array}$ \\
\hline
\end{tabular}

Analysis of different material. Learners can avail themselves of different material (multimedia packages, simulation systems, etc.), so that difficulties can be graded with respect to personal needs, and learners work according to their personal attitude and learning interest. For example, the educator can propose different material on the same topic, and got the learners to choose what material to analyse, in what order, etc., in order to reach a given objective; this may be solution of a problem, analysis of a situation, or preparation of a report, within a fixed time. This kind of activity can help 
learners acquire meta-cognitive capabilities, such as that of evaluating difficulties and reasoning about their own learning strategies.

In this respect, it should be noted that the same kind of work cannot be easily carried out using another kind of material such as books, as the stimulus for the activity mainly lies in the kind of material proposed.

Search activities. Search activities are fundamental in learning to recognise and find sources of information, critically analyse and compare them, and choose those that are relevant to the objectives. This kind of activity is encouraged by the availability of the web for seeking material that can be re-used by the students. One very interesting topic to work on in this way is geography. For example, learners can be asked to plan a trip on the basis of a number of constraints: the number of days to spend, the budget, trip's historical value, museums, sight-seeing possibilities, etc. Using the web, learners can tackle the search, restrict the possibilities on which to focus, go back to the web to analyse further the options selected, then integrate the information with tourist guides and interviews with a travel agency.

\subsection{Learning as a social activity}

Role-play activities. ICT is a helpful tool for conducting collaborative activities where learners take on different roles and responsibilities. A number of activities should be planned so that all learners can try their hand at all roles, thus acquiring a sense of responsibility, the capability to recognise and find learning sources (such as other people), reaching selfconfidence, self-rating capabilities, and flexibility in adapting themselves to a given situation. One example, drawn from our experience in the EU Adapt project Teleconferencing, regards the introduction of teleconferencing to a group of managers of small and medium enterprises (Forcheri et al. 1999). A first experiment consists in the use of the BSCW teleconferencing system (Bentley et al. 1997) to carry out project work in which each participant takes a different role. To make managers acquire autonomous learning capabilities in this area, we get them to use BSCW with different roles and responsibilities. At present, the work is centred on a questionnaire to enterprises; the activities include deciding the enterprises to be interviewed, managing the list of the interviews, analysing the results, preparing the report, etc. Each manager involved in the project takes responsibility for an activity; all of them have to inform the others of the state of play in the activity, ask for suggestions, and give their ideas on the other activities. The co-ordination of the whole activity is entrusted to us. Although still in progress, this work has already produced satisfactory results, in terms of both the awareness of the potential of teleconferencing systems and the 
understanding of the kind of autonomous learning activities required for useful introduction of such systems in enterprises.

Teaching. Giving learners the responsibility of teaching is a very useful assignment for making them aware of the knowledge already possessed, understanding the gap between what is already known and what should be known, understanding the level reached in the mastering of a topic. Asking them to handle this task at the distance using a written form enhances these aspects, and makes it worthwhile to set activities of this kind. An example can be made from our experience within the Qualification 2000 project of the EU Adapt initiative: this is a course designed for working people which aims to give them office automation knowledge and the capability to adapt autonomously to changes in software. The course combined face-to face and distance learning, and we set the trainees distant activities to be done in pair. This was organised so that one of the two had to propose a fixed task for the other, follow up his/her work, and answer requests for explanation. This work yielded very good results in terms of both the learning of the topic and the awareness of the difficulties underlying such learning (Forcheri et al. 1998).

Articulated projects. Working on an articulated project helps people integrate individual work, develop a sense of responsibility, acquire the capability to evaluate time and objectives, and follow a methodological approach in handling a given task. Widely used electronic tools such as word processors, spread-sheets, and automatic presentation systems help the educator to design projects of this kind, in which the final outcome is a product. An interesting example in the school world, is the production of a school magazine, carried out in various Italian secondary schools with very interesting results (AA.VV. 1998). This activity requires participants to work in a well co-ordinated team and to carry out a variety of well defined tasks (writing the editorial and other articles, running a letters page and guest correspondent column, preparing questionnaires for readers, designing layout, writing and choosing comic strips, making up the showcase page, organising news reports, deciding on and preparing pictures). This kind of activity is greatly facilitated by the use of communication and information technology. Students have a number of tasks to perform, especially when the activity is completely entrusted to them, having to decide the kind of software to use, running it, learning how to use a scanner, or a printer, or how to minimise the costs, and so on.

Problem solving activities. As is well known, problem solving is fundamental for acquiring the capabilities of abstracting from examples, setting up autonomous strategies, understanding the need to adopt a methodological approach to a given task. Widely used electronic systems can be used successfully to handle these kinds of activities. For example, in 
secondary-school mathematics education, algebraic activities can be organised using both electronic spread-sheets and symbolic computation systems, the aim being to give students the capability to adopt workable views of problems in light of the objectives, make conjectures and verify them, and compare tools. This kind of work seems to be particularly useful for students who have difficulties in mathematics problem solving (Dettori et al. 1998).

Management activities. Being entrusted with responsibilities is usually fulfilling, and helps to acquire self-confidence and the capability to design strategies for accomplishing a task. Referring to the school setting, a possible proposal in this direction is to give groups of students, in turn, some responsibility in the management of the computer lab, according to a practice usually followed at university level.

As to on-the-job trainees, a possible proposal we tested was to give them responsibility for the collection and editing of the training course notes, or in the distribution of the course written material.

\section{CONCLUDING REMARKS}

ICT, as shown by numerous research in the field (Liao 1995), has the potential to innovate education, but the exploitation of this potential strongly depends on the use. EU and national projects, in our experience, constitute a valuable impulse in this direction, as they help to realise research projects oriented not only to give new insights into the teaching-learning process but also to design methods to transform these new insights into educational practice.

\section{REFERENCES}

AA.VV. (1998) LeoVinci. Giornalino Liceo Scientifica Leonardo da Vinci. (1) 1-4.

Arezzo, D., Forcheri, P., and Lemut, E. (1998) Multimedia tools for in-service self-training of mathematics teachers. Techical. Report. 7/98, Genova, Italy: CNR-IMA.

Bentley, R., Appelt, W., Busbach, U., Hinrichs, E., Kerr, D., Sikkel, K., Trevor J., and Woetzel G. (1997) Basic support for co-operative work on the World Wide Web. International Journal of Human-Computer Studies. 46(6) 827-846.

Bottino, R. M., Chiappini, G., Forcheri, P., Lemut, E., and Molfino, M. T. (1999) Design and reporting on research projects based on information and communication technology. Education and Information Technologies. in press.

Balacheff, N. (1993) Artificial intelligence and real teaching. In C. Keitel and K. Ruthven (eds.) Learning from computers: Mathematics education and technology. Berlin: Springer-Verlag.

Blandow, D. and Dyrenfurth, M.J. (eds.) (1994) Technology education in school and industry. Advanced technology self-learning tools, NATO ASI Series, Berlin: SpringerVerlag. 
Bottino, R. M., Forcheri, P., and Molfino, M. T. (1998) Technology transfer in schools: from research to innovation. British Journal of Education and Technology 29(2) 163-172.

European Commission (1995a) The green paper on innovation, December 1995.

European Commission (1995b) White paper on education and training, November 1995.

Dettori, G., Garuti, R., and Lemut, E. (1998) From arithmetic to algebraic thinking by using a spread-sheet. In R. Sutherland (ed.) Algebraic processes and structure. Dortrecht: Kluwer.

Forcheri, P., Molfino, M. T., and Riccio, F. (1997) Combining hypermedia and network technology to support active vocational guidance, Computer Information Technology 5(1) 51-61.

Forcheri, P., Molfino, M. T., and Quarati, A. (1999) Teleconferencing tools in enterprises: Constraints and opportunities. Proceedings of PEG99, Exeter, UK. 10-12th July 1999.

Forcheri, P., Molfino, M. T., Quarati, A., and Riccio, F. (1998) A computer-based model for continuous training in SMEs. In G. Davies (ed.) Proceedings of IFIP World Congress, Teleteaching '98 31st August-4th September 1998.

Hampel, T., Ferber, F., and Muller, W. H. (1988) mechANImateach - A new approach to the teaching of mechanics, In G. Davies (ed.) Proceedings of IFIP World Congress, Teleteaching'98 31st August-4th September 1998.

Kommers, P. A. M., Grabinger, S., and Dunlap, J. C. (1996) Hypermedia learning environments: Instructional design and integration, New York: Lawrence Erlbaum.

Liao T. T. (ed.) (1995) Advanced educational technology: Research issues and future potential. Nato-ASI Series, Springer.

Noss, R. (1995) Thematic chapter: Computers as commodities. In A. A. diSessa and C. Hoyles (eds.) Computers and exploratory learning. Berlin: Springer-Verlag.

Rekkedaln, T. (1998) Teaching in the electronic college: Some didactic considerations based on feedback from students. In G. Davies (ed.) Proceedings of IFIP World Congress, Teleteaching'98 31st August-4th September 1998.

\section{BIOGRAPHIES}

Paola Forcheri is senior researcher at IMA-CNR (Italy). Her current research regards: education and training in mathematics and informatics, technology based educational systems, continuous training in enterprises. Research is inserted in EC and national projects. She has authored over 80 papers and trade-marks, edited special issues of journals and conference proceedings, and organised international and national conferences.

Maria Teresa Molfino is senior researcher at IMA-CNR (Italy). Her research interest are focused on Computers in Education and on Automated Reasoning. She has written more than 80 scientific papers. She edited special issues of journals and conference proceedings; and she taken part in the organisation of international and national conferences. She is the Italian leader of national and EC research projects. 